\title{
The European committee for the prevention of torture and the gendered experience of imprisonment
}

\author{
Ciara O'Connell ${ }^{1} \cdot$ Eva Aizpurua $^{1}$ (1) $\cdot$ Mary Rogan $^{1}$
}

Accepted: 19 January 2021 / Published online: 23 February 2021

(C) The Author(s) 2021

\begin{abstract}
The European Committee for the Prevention of Torture and Inhuman or Degrading Treatment or Punishment (CPT) is a supranational prison oversight body tasked with carrying out visits to places of detention across Europe. Prisons fall within the remit of the CPT, and much like prisons themselves, CPT prison visits tend to focus on the male experience of imprisonment. However, the experience of imprisonment is inherently gendered and, as such, the experiences, treatment and needs of cisgender men do not necessarily represent those of cisgender women and transgender people in prison. Therefore, it follows that a different approach is also required when it comes to prison monitoring activities carried out by the CPT. This paper introduces CPT standards and the international legal framework on gender and imprisonment. It reflects on analysis of three years of CPT reporting to explore how the CPT considers the gendered experience of imprisonment. To this end, the paper considers the potential impact of the gender composition of CPT delegations, as well as provides a descriptive content analysis of CPT reports to determine how the CPT accounts for gender-specific treatment and conditions in prison. This paper poses questions and provides suggestions around how gender can be made more central across all human rights monitoring bodies operating in the penal field, both internationally and domestically.
\end{abstract}

\section{Introduction}

Since its inception in 1987, the European Committee for the Prevention of Torture and Inhuman or Degrading Treatment or Punishment (CPT) has served as a model for international prison oversight [6]. As a human rights monitoring body, the CPT's activities include visits to detention facilities, the development of standards on treatment and conditions for prisoners and detainees, engagement in high-level talks with Council of Europe member states and, at times, the issuing of public statements

Ciara O'Connell

ciara.oconnell@tcd.ie

1 School of Law, Trinity College Dublin, Dublin, Ireland 
in circumstances of egregious failure to comply with human rights standards [29]. As of September 2020, the CPT has carried out more than 450 visits to places where people are deprived of their liberty across Europe and published over 400 visit reports. In that cisgender men ${ }^{1}$ historically comprise a disproportionate number of people imprisoned in Europe [44], male imprisonment is the norm. This results in the development of prison rules and operations designed to address the needs and experiences of cisgender men in prison. Such an androcentric approach to incarceration subsequently influences how prison monitoring and oversight bodies conduct their work, they too might centre the male experience of imprisonment.

Although cisgender men comprise a significant proportion of imprisoned people, the population of people living in women's prisons continues to grow worldwide [38-40]. Alongside this, the experience of transgender people in prison is one not adequately accounted for and rarely effectively addressed [26, 35]. Cisgender women and transgender people are often incarcerated for different reasons than cisgender men and, once in prison, they have different needs. To effectively identify and assess the needs of cisgender women and transgender people in prison, there is a need for prison monitoring bodies to better institutionalise a gendered understanding of treatment and conditions in prisons. Increasingly, the CPT has taken steps to consider the experience of detention for cisgender women and transgender people in prison, yet this has been done on a more ad hoc rather than systematic basis.

To our knowledge, there currently exists no analysis of how the CPT considers the experience of cisgender women and transgender people in prison. In response to this, the current study offers an assessment of CPT reporting on gender and imprisonment across a wide range of countries. This study adopts an interdisciplinary analytical approach to assess CPT reporting and, as such, it brings together quantitative and human-rights legal analyses to explore the activities of an international prison monitoring body, allowing for a comprehensive articulation of the implications of the quantitative findings. The paper provides an overview of the situation of cisgender women and transgender people in European prisons, as well as examines the international human rights legal framework on standards for women, gender and imprisonment. It then reflects on three years of CPT visit reporting to describe and assess how the CPT considers the gendered experience of imprisonment. To this end, the paper examines the gender composition of CPT delegations over the designated time period to determine if delegation composition has any significant impact on the adoption of a gender focus in CPT reports. Further to that, the paper provides an analysis of CPT reports made public up until

\footnotetext{
1 The term 'cisgender' refers to a person whose gender identity corresponds with the sex the person had or was identified as having at birth. The term 'transgender' denotes a person whose gender identity differs from the sex the person had or was identified as having at birth. The authors use these terms when there is a need to make a clear distinction between the experience of imprisonment for cisgender men, cisgender women and transgender men and women (transgender people). These efforts to distinguish the different groups are not intended to imply transgender women are not women, or that transgender men are not men. Rather, the intention is to (i) make clear the unique experiences and needs of transgender people in prison, and (ii) draw attention to the CPT's limited reporting in the area of transgender prisoners. Where it is not possible or necessary to make a distinction between transgender and cisgender women, such as when discussing the legal framework on gender and imprisonment and when examining CPT reporting and standards on women in prison, the authors make no distinction.
} 
December 2019 following visits to prisons conducted between January 2016 and December 2018. The analysis reveals areas where the CPT accounts for, and fails to account for, gender-specific treatment and conditions in prison. By exploring how the CPT considers the experience of imprisonment for cisgender women and transgender people in prison, this paper identifies and critiques instances where, for example, the CPT does not consistently apply its standards on women, gender and imprisonment, or could do more to explore the intersectional dimensions of imprisonment. The interdisciplinary analysis of CPT reports provided here offers a vehicle for understanding how prison oversight bodies, both national and international, address and respond to the gendered implications of imprisonment. In doing so, the study also seeks to prompt further empirical research intended to explore how the CPT, and other prison oversight bodies, conducts their work. Of particular interest are studies examining how this work is perceived by oversight beneficiaries.

\section{Cisgender women and transgender people in prison}

The population of people living in women's prisons in Council of Europe member states has remained relatively consistent over the past two decades, at approximately five percent of the overall prison population. In 2017, it was estimated that 100,000 people were imprisoned in women's prisons across Europe [39]. However, this does not necessarily consider the number of transgender women who live in men's prisons across the region. Currently, no reliable estimate exists of the population of transgender people in Europe's prisons. However, a recent study in England and Wales revealed that approximately two percent of prisoners surveyed in adult male prisons identified as transgender [17].

The circumstances leading to the imprisonment of cisgender women and transgender people are often underscored by the discrimination and inequality they face in society [31]. Cisgender women are more likely to live in poverty, to be primary child carers, and to have suffered physical and sexual abuse prior to imprisonment [8]. Notably, the crimes they commit are generally of a different nature as compared to cisgender men, as is the seriousness of their offences. Cisgender women are more likely to commit non-violent offences, such as theft and fraud. In that the crimes that cisgender women commit are generally of a less serious and violent nature, there is reason to argue that they pose less institutional risk while in prison [45]. Overall, cisgender women in prison are perceived to be doubly deviant because not only are they criminals, but they are also "failed mothers" and "bad wives",they have "offended against their femininity" $[9,28]$, breaking not only legal but also social norms.

Transgender people are incarcerated for various reasons, but systemic discrimination is often an underlying factor [41]. Transgender people face discrimination when it comes to housing and employment opportunities and are also likely to face harassment and hate-based violence. As a result, transgender people are at risk of dropping out of school, experiencing economic uncertainty and criminalisation [42]. Many transgender people face problems at home, find it difficult to secure employment and 
are unable to access safe support services. This amalgamation of discriminatory factors may result in transgender people finding themselves homeless and unemployed. In such situations, transgender people may turn to working in illegal economies, which can lead to their imprisonment [24].

Once in prison, cisgender women and transgender people have different personal and criminogenic needs as compared to cisgender men. For instance, they require gender-specific healthcare services and support, including hygiene products and gynaecological needs, as well as the adoption of trauma informed and gender specific practices and psychological support [34],UN Bangkok Rules 10, $11,12)$. People in prison who are pregnant or are parents may require maternity care and provisions that allow for nurturing interaction with children. Cisgender women and transgender people are also at greater risk of sexual assault while in prison and, as such, require particular protections and staffing measures $[19,43] .^{2}$ Transgender prisoners require support services specific to their needs, including accommodation that allows them to live permanently in their gender and the enactment of measures designed to combat transphobic harassment. Further, ensuring the safety of cisgender women and transgender prisoners requires proactive initiatives to address stereotyping and discriminatory behaviour perpetrated by staff and prisoners alike [27].

\section{International legal framework}

The international legal framework adopted to address the treatment and conditions of women in prison is increasingly well developed; although it makes limited reference to the specific needs of transgender people in prison. This section provides an overview of United Nations and European human rights instruments specific to the rights of prisoners, with the objectives being to (i) draw out how and to what extent they enshrine gender considerations in the context of imprisonment; (ii) substantiate the need to develop a more robust human rights framework applicable to transgender people in prison; and (iii) highlight the limitations of the human rights framework in its ability to improve the treatment and conditions of prisoners. Following from this, Sects. 4 and 5 provide an examination of the CPT as it relates to the Committee's activities on women, gender and imprisonment.

The United Nations legal framework specific to the rights of prisoners is primarily comprised of the 1984 Convention against Torture and Other Cruel, Inhuman or Degrading Treatment or Punishment (UNCAT) [50], the 1988 Body of Principles for the Protection of All Persons Under Any Form of Detention of Imprisonment [46] Principles), the 2015 Standard Minimum Rules for Prisoners (known as the Mandela Rules) [52], and the 2011 Rules for the Treatment of Women Prisoners and Non-Custodial Measures for Women Offenders (the Bangkok Rules) [51]. UNCAT does not contain gender-specific provisions, and the 1988 Principles note on just one

\footnotetext{
${ }^{2}$ Some studies, however, have not found differences in the frequency of sexual assaults between males and females, see C. Struckman-Johnson \& D. Struckman-Johnson (2006). A comparison of sexual coercion experiences reported by men and women in prison. Journal of Interpersonal Violence, 21(12), 1591-1615. https://doi.org/10.1177/0886260506294240.
} 
occasion (Principle 5) the need to provide different treatment to women prisoners. The 2015 Nelson Mandela Rules offer an assessment, albeit limited, of the specific needs of people in women's prisons. For instance, Rule 28 provides for the need to ensure special accommodation for prenatal and postnatal care in women's prisons. With respect to the treatment of transgender people in prison, Rule 7 highlights the need to record prisoner information in a way that respects the "self-perceived gender" of the prisoner.

The Bangkok Rules, of which there are 70, represent the most comprehensive effort to account for the treatment and conditions of women in prison [9]. These Rules encompass a wide breadth of issues, including “women's specific hygiene needs", gender-specific healthcare including mental health care services and sexual and reproductive healthcare, gender-based training for prison staff, and conditions necessary to promote opportunities for women to spend time with their children (Rules 5, 6, 10-13, 33, 49-52). The Bangkok Rules also account for the unique needs of minority, indigenous and foreign national women in prison (Rules 53-55). However, by neglecting to provide rules that address the specific (physical and mental) healthcare, accommodation and security needs of transgender women, the Bangkok Rules miss a significant opportunity to protect the rights of all women in prison. The United Nations legal framework on the rights of prisoners is supplemented by the Principles on the Application of International Human Rights Law in Relation to Sexual Orientation and Gender Identity [49]. These Principles, while not adopted by the United Nations General Assembly, respond to the inconsistent application of human rights standards as they concern issues of sexual orientation and gender identity. Regarding the gendered experience of imprisonment, the Yogyakarta Principles incorporate recommendations specific to the treatment of transgender people in prison (Recommendations 9 and 10), which include the need to "ensure, to the extent possible, that all prisoners participate in decisions regarding the place of detention appropriate to their sexual orientation and gender identity" (Recommendation 9(c)).

Alongside the United Nations legal framework, the Council of Europe operates a regional framework on the rights of prisoners. The CPT is the region's foremost authority on the monitoring of treatment and conditions in prisons and, as such, is discussed in more detail in Sects. 4 and 5. Alongside the monitoring activities of the CPT, the European Court of Human Rights (ECtHR) has on several occasions examined the European Convention on Human Rights as it applies to the rights of prisoners. For instance, the Court has examined the question of whether differential treatment between cisgender men and women in prison is in breach of the guarantee of equality [69-71]. Interestingly, these cases were initiated by men who argued they had received unfavourable treatment as compared to women in prison. Surprisingly few cases have examined specific instances of allegations of ill-treatment made by women prisoners while in prison. In one of the few available examples, Uyan v Turkey [68], the Court determined a breach of Article 3 (prohibition of torture and inhuman or degrading treatment or punishment) in response to the applicant's claim that she had been subjected to inhuman and degrading treatment after being compelled to wear handcuffs during a gynaecological exam. To-date no cases have 
examined issues involving transgender prisoners, although there are two cases on transgender prisoners' rights currently pending before the Court. ${ }^{3}$

Prisoner rights are also articulated by the Council of Europe through Recommendations, ${ }^{4}$ including the 2020 revision of the 2006 European Prison Rules [48]. The EPRs incorporate a much-needed elaboration of standards on women's imprisonment in Europe. For instance, the EPRs consider that special provision be made for the sanitary needs of women (Rule 19.7), that gender-based discrimination not factor into the type of work provided for prisoners (Rule 26.4); and that prisoners are only to be searched by staff of the same gender (Rule 54.5). Further to these, Rule 34 of the EPRs establishes specific provisions to address the situation of women prisoners and their minority status in prisons. It provides that authorities pay particular attention to the requirements (physical, psychological, vocation and social) of women when making decisions about their detention. It also mandates that states ensure access to special support services for women who have experienced physical, mental or sexual abuse.

The international legal framework on the rights of prisoners and people deprived of liberty is well-developed but finds its limitations when applied to the gendered experience of imprisonment, especially when considering the needs of transgender people in prison. This raises questions about the capacity of the human rights legal framework to improve treatment and conditions of cisgender women and transgender people in prison. First, prisoners may not conceptualise of rights in ways that align with the legal framework, and officials may use rights-based language while, in reality, employing poor practices [32]. Prisoners might not be aware of their human rights protections [22], 116, [36] or may not know how to wield them in an effort to improve their situation of imprisonment. Second, rights-based penal reform has faced increased criticism as scholars challenge the utility and benefit of such an approach to improve treatment and conditions in prisons [3, 7]. Central to this critique are concerns about the expansion of penal control resulting from uncritical adoption of a rights-based approach to penal policy reform, despite an existing 'disjuncture between penal governance and human rights knowledge' [3]. That is, the international and European human rights legal frameworks on the rights of prisoners may very well be used by penal policymakers as justification for increased penal expansion [4]. In relation to cisgender women and transgender people, a rightsbased effort to protect the health and well-being of prisoners may be used as rationale to build new prisons, or to implement practices that prove harmful in the context of prison. Despite these challenges, the international human rights legal framework offers a set of standards by which it is possible to uphold a benchmark for acceptable treatment and conditions and gauge state compliance with human rights standards (although these may require critique). Furthermore, the framework signals to states, government authorities and prisoners themselves, that prisoners require specific protection and treatment. However, the opposite signal is sent when the human rights framework neglects to include the specific needs of certain populations, such as cisgender women or transgender prisoners.

\footnotetext{
3 See, ECtHR, GG v Turkey, Appl. no. 10684/13 and ECtHR, Bogdanova v Russia, Appl. no. 63378/13.

4 See, Council of Europe Recommendations: Council of Europe Rec(82)17; Rec(89)12; Rec(93)6; Rec1257(1995); Rec(98)7; Rec(99)22; Rec1469(2000); Rec(2003)23; Rec(2012)12; Rec(2018)5). https ://www.coe.int/en/web/prison/conventions-recommendations.
} 
To explore and interrogate the limitations of the human rights' legal framework, there is a need to apply 'ethnographic attention to bureaucratic spaces of punishment' [3], 401). This paper offers a comprehensive analysis of CPT reports, thereby identifying inconsistencies and gaps in how the CPT conceptualises of and seeks to improve the gendered experience of imprisonment. As such, it provides one part of a much-needed critical analysis of the extent to which the human rights framework incorporates the needs of cisgender women and transgender people in prison. In doing this, the paper provides a starting point for further study that measures how the human rights legal framework impacts on people in prison.

\section{Women, gender and the CPT}

A key component of the European legal framework on prisoners' rights is the European Committee on the Prevention of Torture and Inhuman or Degrading Treatment (CPT or "Committee"). This human rights monitoring body was established in 1987 by the European Convention for the Prevention of Torture and Inhuman or Degrading Treatment or Punishment (ECPT) [47], which is ratified by all 47 Council of Europe member states. The CPT has a specific mandate to carry out visits to "examine the treatment of persons deprived of their liberty with a view to strengthening, if necessary, the protection of such persons from torture and from inhuman or degrading treatment of punishment" (ECPT Article 1). The CPT conducts visits in all Council of Europe member states and may visit any place where "persons are deprived of their liberty by a public authority" (ECPT Articles 2, 8(1)). As a human rights monitoring body, the CPT is not a judicial entity, but rather its mandate is to prevent violations of Article 3 of the European Convention on Human Rights [10, 29]. Its primary activities include visiting detention facilities and engaging in state dialogue through reporting to prevent ill treatment and poor conditions. Alongside its visit and corresponding reporting activities, the CPT engages in high-level talks with government officials and, in rare cases, issues public statements in instances where states fail to improve treatment and conditions [30].

CPT visits take two forms: periodic visits, where the state is made aware of the visit a year in advance, and ad hoc visits, which occur with very little notice. Whereas all member states receive a periodic visit approximately every four to five years, ad hoc visits are carried out when 'required in the circumstances' (ECPT Article $7(1)$ ). Such visits are triggered when there is an underlying issue of particular concern in a specific institution or when a locality requires more immediate attention [29]. CPT reports and government response reports remain confidential unless the state allows the CPT to make the reports public. The CPT presents its assessment and observations using three types of statements, which hold different weights:

i. a comment noting a particular situation;

ii. a request for information from state authorities to follow up on an observation made during a visit; and

iii. a formal recommendation made to officials to change a practice or situation. 
A statement in the form of a recommendation requires states to respond with a form of action, which means that the CPT reserves these statements for issues that demand attention. Consequently, comments made by the CPT that do not warrant a distinct recommendation may be perceived to carry less weight.

While the CPT is lauded for its efforts to protect the rights of those deprived of liberty [12], it has thus far been inconsistent in its approach to monitoring treatment and conditions for cisgender women and transgender people in prison. ${ }^{5}$ The same holds true as regards scholarship focused on the CPT, which has explored themes such as the relationship between the CPT and the European Court of Human Rights,analysis of CPT reporting and standard-setting; and assessments of government responses to and implementation of CPT recommendations [1, 2, 6, 11, 13, 29].

The CPT has adopted two instruments outlining the Committee's standards for monitoring treatment and conditions of women in prison: Women Deprived of Their Liberty published in 2000 (CPT [66], and the Women in Prison Factsheet published in January 2018 (CPT [67]. The Women in Prison Factsheet (hereafter "the Factsheet"), which largely elaborates on the standards established in the 2000 report, recognises from the outset that "women must enjoy the fundamental right not to be discriminated against - directly or indirectly - on the grounds of their biological sex or gender". The Factsheet provides standards intended to be read in conjunction with those outlined in the European Prison Rules, the Bangkok Rules, the Nelson Mandela Rules and the caselaw of the European Court of Human Rights. Despite the CPT's efforts to develop a set of standards for the imprisonment of women, they are not consistently applied through the CPT's reporting mechanism, as is illustrated below. That being said, the CPT has, on occasion, examined and reported on the treatment and conditions of transgender people in prisons.

\section{Locating gender in CPT visit reports}

Between 2016 and 2018, the CPT carried out 55 country visits and produced 54 visit reports. As of December 2019, the CPT published 45 reports following these incountry visits conducted between 2016 and 2018. ${ }^{6}$ Over the same three-year period, the CPT held 13 high-level talks with Council of Europe member states and issued Public Statements to Belgium and Russia. The analysis conducted in this paper considers reports issued by the CPT following country visits conducted between January

\footnotetext{
5 Given the CPT's underdeveloped reporting on transgender people, it is not always possible to specify whether CPT reporting on the treatment of transgender people in prison refers to transgender women or transgender men. Additionally, it is not clear in some instances if CPT comments are made in relation to transgender prisoners living in men's or women's prisons. In these instances, the CPT's ambiguity makes it impossible to determine if the comment is being made in reference to transgender women or men. For more on the "dilemma of difference" inherent to imprisoning women in men's prisons, see J. Sumner and L. Sexton (2016). Same difference: The "dilemma of difference" and the incarceration of transgender prisoners. Law and Social Inquiry, 41(3), 616-642.https://doi.org/10.1111/1si.12193.

6 Two visits carried out to Greece in the same year were combined into one report. The CPT carried out visits to nine countries between 2016 and 2018 that did not result in a published report by December 2019, these include: two visits to Russia (2016), Turkey (2016), Russia (2017), Turkey (2017) France (2018), Hungary (2018), Spain (2018) and Turkey (2018).
} 
2016 and December 2018, which were made public up until December 2019. Drawing from all visits conducted by the CPT during the 2016 to 2018 time period, the authors selected $31 \mathrm{CPT}$ visit reports for analysis. These reports fulfil three selection criteria: (i) each report includes a visit to at least one prison; (ii) each report includes visits to prisons that housed women prisoners in the prison (this included transgender people in men's prisons when noted by the CPT); and (iii) each report was published up until December 2019. The objective of examining three years of CPT reporting is to explore how the CPT identifies, articulates and responds to the gender-specific needs of women and transgender people in prison during the time in which the body itself developed the women in prison standards.

CPT observations that specifically reference women's prisons or women's units, or that mention women and/or transgender people in prison are referred to as 'gender-sensitive observations'. Once 'gender-sensitive observations' were operationalised, thematic areas were defined amongst the authors. In line with previous empirical research on CPT reports $[2,25]$, the analysis conducted here disaggregates CPT findings based on their thematic content. By way of example, the below recommendation is separated into two thematic areas (conditions of detention and activities, education, and work):

The CPT trusts that the Estonian authorities will take the necessary steps to ensure that the Mother and Child Unit in the new Tallinn Prison will be designed as a separate, closed-off section, which also comprises a suitablyequipped nursery or kindergarten-type facility; this may also facilitate the participation of mothers in work and other activities inside the prison [58] II56).

The second author set up the dataset while the first author acted as the primary coder. To ensure the codes were applied as intended, the second author reviewed the codes following initial coding of five reports (16.1\%). Any inconsistencies or unclear instances were discussed and solved by all the authors. In addition, the codes were revised on an ongoing basis to ensure consistency across the reports.

The analysis of CPT reports conducted here explores how the CPT considers the gendered experience of imprisonment in three ways.

i. It examines CPT observations and the gender composition of CPT visit delegations to determine what impact, if any, the gender composition of delegations has on the CPT's reporting on issues related to cisgender women and transgender people in prison.

ii. It assesses how the CPT addresses gender-related issues in prisons within its reporting mechanism, with specific reference to CPT recommendations.

iii. It explores how the CPT applied the 2018 Women in Prison Factsheet standards in relevant 2018 visit report recommendations.

By identifying instances where the CPT does not consider, or perhaps insufficiently considers, the gendered experience of imprisonment, it becomes possible to uncover opportunities where the CPT can better institutionalise a gendered understanding of treatment and conditions in prisons. 


\section{Delegation composition}

The question of the impact of gender representation is one that has not yet been addressed in relation to the CPT and its reporting activities. However, this question has permeated the judicial space, offering a foundation on which to raise the question, why gender? Research on gender representation in judiciaries has assessed trends in judicial benches over time, unpacked the grounds on which governments nominate individuals, as well as attempted to determine what difference, if any, greater gender representation and parity makes in terms of expanding gender justice [18, 23, 33, 37]. Greater representation of women has symbolic meaning, as well as practical and substantive impact. For instance, greater representation of women increases the legitimacy of institutions because they become more representative of society and signal an equality of opportunity. Some scholars also argue that women are more empathetic when engaging with other women and that they bring a "gendered sensibility" to the process of decision-making [18]. However, these arguments are countered by scholars who argue that women may not comport with a gender-sensitive approach to decision-making because of factors such as their training, understanding of the law and the need to distance themselves from their difference in order to establish authority and be taken seriously. While studies of the judiciary do not offer a definitive conclusion as to the impact of gender representation, the question of whether the gender composition of the delegations influences CPT reporting can only be answered empirically. In an effort to contribute to examine the influence of gender representation, ${ }^{7}$ this section analyses the impact of gender composition of CPT delegations to determine how, if at all, representation of women in CPT delegations impacts on the amount of gender-sensitive observations.

This analysis considers $31 \mathrm{CPT}$ reports corresponding to CPT visits carried out between January 2016 and December 2018. CPT visits are carried out by Committee and Secretariat members who are often accompanied by independent experts. The composition of CPT delegations is based on several factors, including Committee member expertise (legal, medical, psychiatry, prison service, etc.), nationality, language and specific thematic areas of interest for CPT assessment during a visit [6]. Depending on the size of the country and the type of visit (periodic and ad hoc), the 31 CPT delegations examined here comprised anywhere from three to ten individuals (with an average of eight). That being said, the analysis does not account for additional characteristics within CPT delegations, such as age, race/ethnicity, professional background, expertise and experience. This is because, while variables aside from gender are likely to influence how CPT delegates carry out their work, gender representation within prison monitoring bodies is a primary concern within the legal framework on prisoners' rights. For example, the UN Bangkok Rules (Rule 25.3) articulate the need to include women in monitoring activities because this ensures "that the provision of services addressing women prisoners' specific needs are properly inspected by

\footnotetext{
7 See, GQual: Campaign for Gender Parity in International Representation, CEJIL. www.gqualcampa ign.org/home/. Accessed 15 September 2019.
} 
a person of the same gender, as well as encourage(es) the receipt of complaints from women prisoners, who may feel inhibited in coming forward if all members of the monitoring body were to be male".

The analysis of $31 \mathrm{CPT}$ visit reports revealed that gender-focused observations represented $0 \%$ to $38.1 \%$ of the total observations made by the CPT in the context of prisons between 2016 and 2018. On average, this amounts to $6.2 \%$ of gendersensitive observations in 2016 reports, $9.3 \%$ in 2017 and $7.1 \%$ in 2018 (overall $2016-2018=7.7 \%$ ). Potential differences in the proportion of gender-sensitive observations across the years were tested using analyses of variance. The results indicate no significant differences, suggesting that the proportion of gender-sensitive observations were comparable across the years $(\mathrm{F}(2,28)=0.387, p=0.683)$. Interestingly, in all three years of reports analysed, the CPT issued reports in which visits were made to prisons accommodating women yet did not include gender sensitive observations (see Fig. 1).

The CPT delegations that carried out the 31 visits were comprised, on average, of $63.5 \%$ men and $36.5 \%$ women, with the proportion of women in the delegations increasing slightly from over one-third in 2016 and 2017 to $41.5 \%$ in 2018 (see Fig. 2). Despite the noted increase in women's representation within CPT delegations in 2018, the differences across the years did not reach statistical significance $(\mathrm{F}(2,28)=1.134, p=0.336)$. It was only in 2016 that a single delegation was composed of more women than men (55.6\% of women). In all the remainder visits across the three-year timespan, the proportion of men was higher $(77.4 \%)$ or equal to that of women $(19.4 \%)$.

In addition, there is a very weak and non-significant association between the percentage of women on CPT delegations and the percentage of gender observations made in corresponding CPT reports, as indicated by Pearson's correlation coefficient $(r=0.102, p=0.585)$. This finding indicates that the composition of the delegation is unrelated to the weight that gender observations have in CPT reports. Figure 3 displays the relationship between these two variables and shows no clear patterns

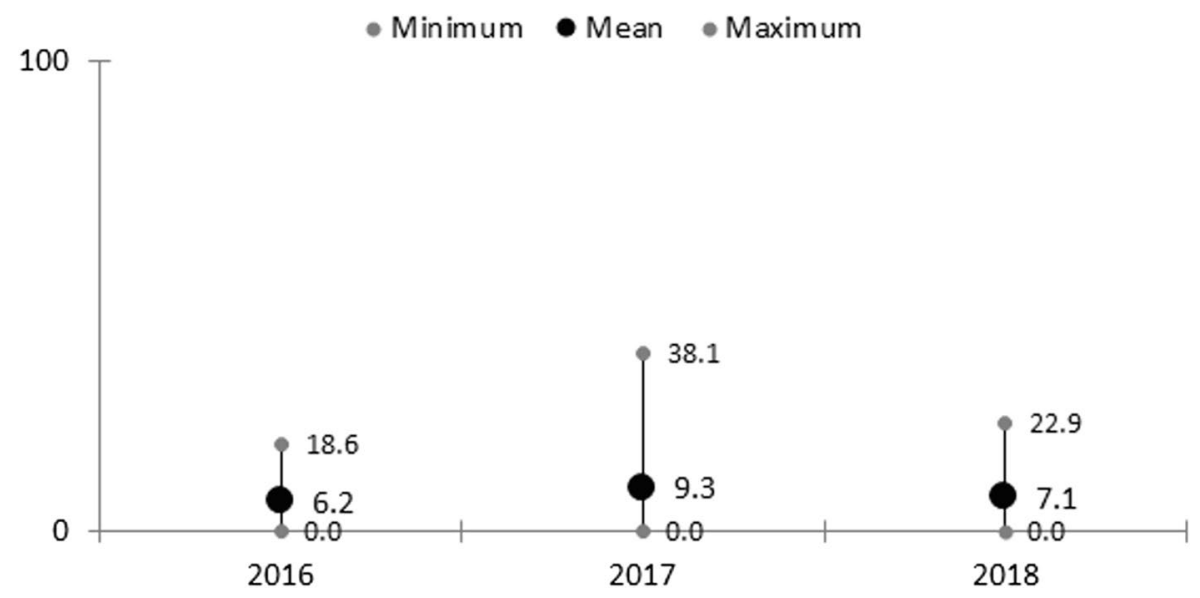

Fig. 1 Gender-sensitive observations, by year 


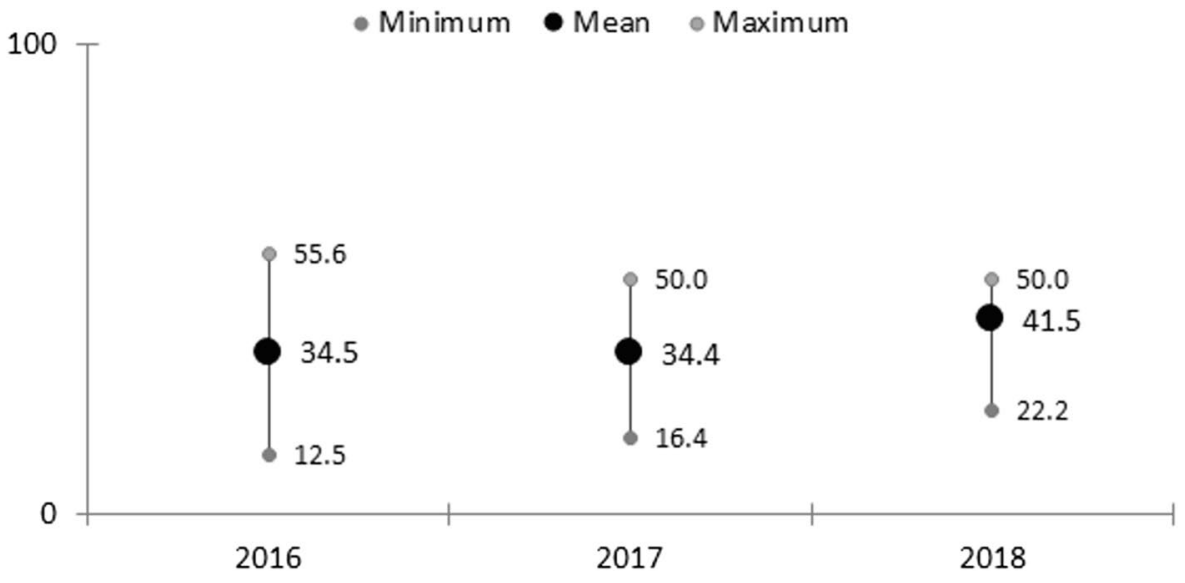

Fig. 2 Women on CPT delegations by year

either over time or between the composition of the delegations and the proportion of gender-sensitive observations.

As mentioned above, greater gender representation within the CPT membership holds value aside from its potential to increase the gender focus within CPT visits and reporting. However, it is notable that in CPT reports in which the proportion of gender-sensitive observations is above average $(>7.7, n=9$ reports), the percentage of women on CPT delegations is also above the average $(40.3 \%$, with a minimum of $28.6 \%$ and a maximum of $50 \%$ ). It is also of interest that the composition of the delegations in the three reports with zero gender-sensitive observations had a representation of women above the average (50\%, 44.4\%, and $44.4 \%)$.

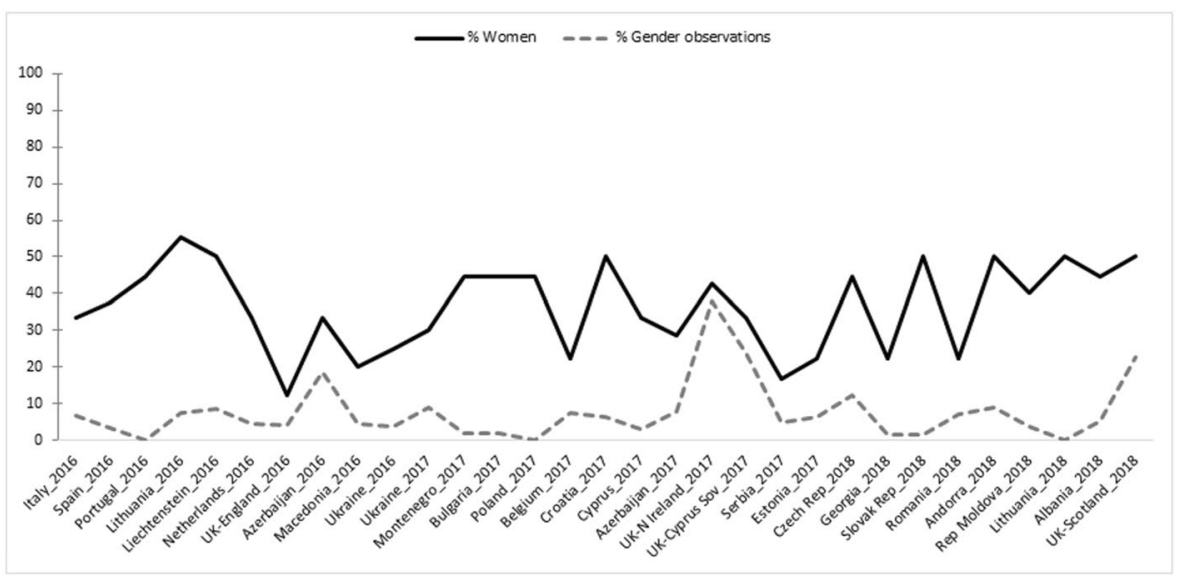

Fig. 3 Composition of the delegations and gender observations 


\section{How CPT reporting addresses gender in prison}

Building on the above analysis of CPT delegation gender composition and its impact on gender observations in CPT reporting, this section delves into the selected 31 CPT reports to analyse how the CPT considers the gendered experience of imprisonment. Of the 45 reports made public over the designated time period, 31 included visits to prisons that, according to the CPT, housed women and/or transgender people $(68.9 \%)$. Of these 31 reports, $90.3 \%$ included gender-sensitive observations (28 of the 31 reports). However, in $50 \%$ of the cases gender observations comprised less than $6 \%$ of the total observations made (median $=5.3$ ). These numbers indicate that, while the CPT monitors the situation of incarcerated women across Europe in the vast majority of its visits, it does not necessarily do so consistently or to the same extent.

As noted above, not all CPT observations carry the same weight when it comes to state action. Only recommendations require state responses in the form of change to current practice. ${ }^{8}$ While the CPT may issue several comments on a given situation, it does not necessarily always provide an adjoining recommendation or request for information. This is very clear in the context of gender observations, where comments represent $61.8 \%$ of all gender observations $(n=201)$ and recommendations represent nearly half of that at $31.4 \%(n=102)$. The remainder $(6.8 \%, n=22)$ are requests for information. To understand how the CPT examines gender in the context of imprisonment, this section explores the thematic areas in which the CPT makes its recommendations, and highlights how the CPT conceptualises the gendered experience of imprisonment.

\section{CPT recommendations on women and gender}

Drawing from Lappi-Seppälä and Koskenniemi [25] and Aizpurua and Rogan's [2] work, which develop categories by which to analyse CPT observations, CPT gender-sensitive recommendations are analysed here across seven thematic areas: healthcare,activities and programmes,conditions of detention; staffing; discipline and security; treatment; and contact with the outside world. Content analysis of 31 CPT reports indicates that between 2016 and 2018, CPT recommendations emphasised three focus areas: conditions of detention (29.9\% of the total observations and $29.4 \%$ of the total recommendations), activities and programmes (21.2\% of the observations and $26.5 \%$ of the recommendations), and health (18.5\% of the overall observations and $22.6 \%$ of the overall recommendations) (see Fig. 4). When compared to studies that do not specifically focus on the gendered nature of CPT observations, important differences emerge. For instance, in our analysis of gendersensitive recommendations, discipline and security receive the lowest proportion of CPT observations, whereas other studies identified this as one of the CPT's principal focal areas. Conversely, activities and programmes were the second most-referenced

\footnotetext{
8 The Committee has the power to issue Article 8(5) immediate observations to recommend immediate state action during, or after a CPT visit. Article 8(5) observations are included as recommendations for analysis.
} 
III Overall observations $\mathbf{a}$ Recommendations

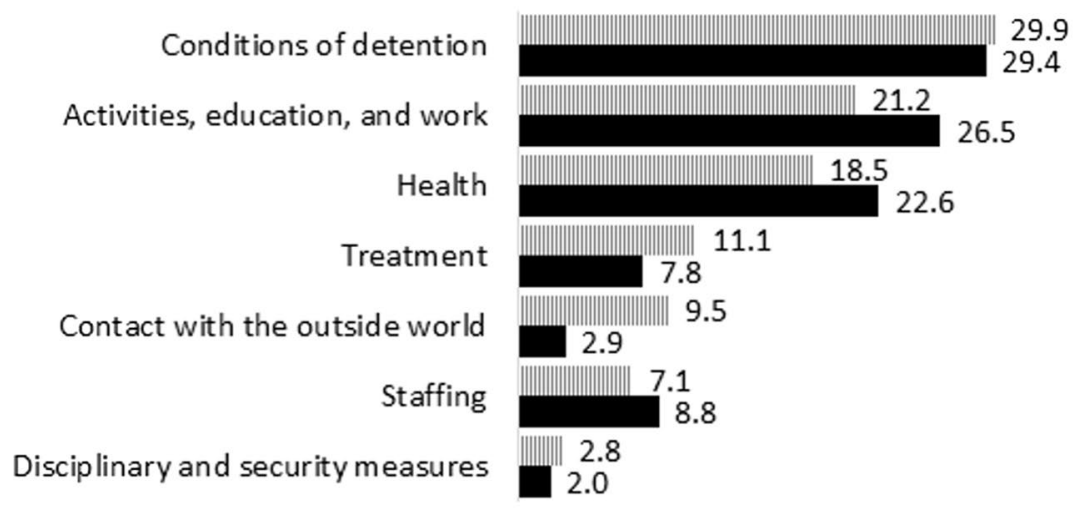

0.0

40.0

Fig. 4 Gender-sensitive observations by thematic area (\%)

thematic area across gender-sensitive recommendations $(21.2 \%$ of the observations and $26.5 \%$ of the recommendations), but comprised less than $6 \%$ of CPT observations in more general studies of CPT observations. Whether this difference in how the CPT approaches the gendered experience of imprisonment is the result of expected or actual differences warrants further research.

The CPT has drawn attention to a number of specific issues across the seven themes outlined above. For example, the CPT has called for the ending of vaginal exam practices (CPT Azerbaijan [53] I[83), and improvements in the gender balance of prison officer staffing (CPT Azerbaijan [54] II67,CPT Romania [59] I[102). The CPT has also raised concerns about de facto isolation/solitary confinement in instances where the numbers of women in prison are so low that there are very few possibilities for women in prison to interact with others [56] I[40, [60] I[52). Alongside these, the situations of mental health and motherhood and pregnancy in the prison context are seemingly primary concerns for the CPT. On the other hand, CPT observations on the situation of transgender people provide less substantive inquiry.

\section{CPT specific focus areas on women and gender}

Motherhood and pregnancy The analysis of 31 CPT reports reveals an emphasis on the situation of women and their children in prison. The CPT has recommended that new facilities be built for mothers and their children in prison, as well as noted that such facilities should aim to be non-carceral in design. By way of example, the CPT issued the following recommendation to the Italian authorities following its 2016 visit:

The CPT recommends that the Italian authorities allocate the necessary funding for the establishment of protected family houses ("case famiglia protette") 
with a view to ensuring that all detained mothers with children are held in a suitable and non-carceral setting, as set out in Law No. 62 of 2011 [61] I[73).

In relation to mothers with children who live outside the prison, the CPT issued recommendations concerning contact with the outside world. For instance, the CPT recommended, "that steps be taken to ensure women prisoners with children can effectively maintain phone contact with them by adjusting the times at which such calls can take place" [64] I[86). The CPT also commented on the need to provide gynaecological healthcare for pregnant women in prison [59] I[114), as well as deemed it inappropriate for a mother and baby to live amongst the general prison population [64] I[71).

While CPT gender-focused observations place a significant emphasis on the experience of motherhood in prison, the CPT notes in the Factsheet that this heavy emphasis "should not be understood as an endorsement by the CPT of the imprisonment of pregnant women or mothers, with or without their young children. On the contrary, the Committee has [...] recommended that alternatives to detention be imposed." That being said, the CPT's only reference made concerning alternatives to imprisonment for mothers across the three years of reports analysed, is in the form of a request for information: "The Committee also wishes to receive information on the measures taken by the Belgian authorities to give preference to alternatives to imprisonment for mothers with young children" [55] I774).

Mental health Throughout its visit reporting in 2017 and 2018, the CPT consistently noted the situation of psychological healthcare and mental well-being for women in prison. The CPT recommended that efforts be made to provide psychosocial support to women subjected to physical, mental or sexual abuse [59] I[100, [64] I[72) as well as recommended that women placed in de facto solitary confinement be given regular access to a psychologist [56] II40, [60] I[52). Additionally, the CPT issued recommendations in severe mental health situations, such as the situation observed during the 2018 UK-Scotland visit, where the CPT recommended.

the Scottish authorities take the necessary steps towards addressing the specific needs of female prisoners with personality/behavioural disorders through introducing therapeutic tailor-made programmes.

The Scottish authorities, the SPS, the NHS, the judiciary, and social services need to work together to protect these women inmates, suffering from personality and behavioural disorders, and/or having a history of self-harming, abuse and abandonment. Where such prisoners are not eligible for transfer to a psychiatric hospital, a multi-faceted approach should be adopted, involving clinical psychologists in the design of individual programmes, including psycho-social support and treatment.[65] I[94).

The CPT made 11 references within recommendations that specifically address psychological healthcare for women in prison [56] II40, [59] II100, [60] II52, [64] II72, 73, 79, [65] I[90, 94, 95, 96 and 120). However, the CPT reports analysed do not draw out how the experience of imprisonment itself negatively impacts mental 
health, a finding supported in a number of studies $[5,15,16]$. Such an omission may have significant implications for cisgender women and transgender people in prison in that the CPT itself has determined that prisons are designed for cisgender men. Although the CPT pays particular attention to the situations of cisgender women's mental health and motherhood in prison, it has not given similar consideration to the specific experience of imprisonment for transgender people.

Transgender people The CPT examined the situation of transgender people in prison within two of the 31 analysed reports [62] I995, [63] I799). In one instance, the CPT commented on the situation of a transgender woman in Spain who had been accommodated for a year in a male prison wing despite her request to be transferred to a women's unit. The CPT acknowledged that, "during this period of time, prison officers apparently verbally abused her several times and insisted on her wearing men's clothes." In response to this observation, the CPT recommended to the Spanish authorities that "custodial staff should be reminded of their duty to respect the specific gender identity of transgender prisoners, in particular in terms of accommodation, clothing and by addressing them with their chosen name."

On the other occasion, in the context of the 2016 UK-England visit, the CPT commented on "positive developments" made in relation to transgender prisoners in a men's prison, but did not specify whether the individuals referred to were transgender women, transgender men or both. This is an issue worth raising because the CPT made no mention of visiting women in its report, but may very well have visited women prisoners who are transgender and living in the men's prison; which would essentially render women invisible in the demographics of the prisons visited. The CPT noted that transgender people in prison were supported by staff in a variety of ways, including by.

ensuring that make-up and wigs were available if requested, inviting prisoners to increase staff awareness of transgender issues, ensuring different shower times, creating prisoner equality representative roles for transgender prisoners and monthly meetings with custodial managers to check on their well-being.

In the report to the UK government, the CPT did not comment on possible areas of improvement for the treatment of transgender people in prison, nor did it make any related recommendations.

These two reports in which the CPT examines the treatment and conditions of transgender people do not explore other relevant issues, such as healthcare and sanitation needs and the impact of being imprisoned as a transgender woman in a men's prison [20]. Given that standards on transgender people in prison are not developed in the international legal framework on prisoner rights, the CPT missed an opportunity to provide guidance and best practice to domestic policymakers and national prison oversight bodies in the area of transgender prisoners' rights.

It seems that from the analysis of 31 CPT reports that there is no standardized approach for how and when the CPT addresses gendered issues in prison. Indeed, this is a criticism applicable to all oversight bodies working in the area of deprivation of liberty generally. Additionally, it is evident that CPT reporting on gender in prison has thus far neglected to identify, assess and account for the experience of 
imprisonment as it intersects across gender and other identifying characteristics, such as race/ethnicity, age, ability, sexuality and socioeconomic status. This gap in the CPT's assessment of treatment and conditions in prisons serves to obfuscate the compound discrimination minority groups experience within an already marginalised population within the prison. It would be beneficial for the CPT to adopt a consistent and standardised approach within its reporting in order to describe and analyse issues relevant to prisoners across the spectrum of prison population demographics.

Further, the analysis provided above highlights issues around the CPT's reporting methodology. For instance, it is unclear at what point the CPT regards a particular situation to be worthy of a recommendation, and it is also not entirely evident in which circumstances the CPT elects to address treatment and conditions of cisgender women and transgender people in prison. The lack of a clear criteria and structure to analyse the gendered experience of imprisonment is indeed a gap in the CPT's oversight mandate. Perhaps the recent publication of the Women in Prison Factsheet Standards illustrates a turning point in how the CPT intends to assess treatment and conditions of cisgender women and transgender people in prison.

\section{Applying the women in prison factsheet standards}

The CPT's publication of the 2018 Women in Prison Factsheet may be an indication that the CPT intends to make a concerted consistent effort to assess treatment and conditions relevant to women in prison. The Factsheet acknowledges that prison rules and prison facilities are "developed for a prison population in which the male prisoner is considered to be the norm". While noting that the standards outlined in the Factsheet do not cover the full range of necessary standards applicable to all people in prison, it clearly expresses that "many of the issues addressed may also apply by analogy to other categories of detained prisoners, such as transgender or female juvenile prisoners". The Factsheet develops seven standards to ensure proper treatment and conditions for adult women in prison: (i) appropriate accommodation; (ii) equal access to activities; (iii) adequate hygiene and health care; (iv) ante-natal, post-natal and child care; (v) gender-sensitive prison management, staffing and training; (vi) gender-sensitive personal searches; and (vii) contact with the outside world. The development of the Factsheet provides an opportunity to see how, and to what extent, the CPT applied its standards within its 2018 visit reports. The following review examines recommendations included in published reports from 2018 visits to Albania, Andorra, the Czech Republic, Georgia, Lithuania, Moldova, Romania, the Slovak Republic and UK-Scotland. ${ }^{9}$ Cumulatively, the prisons visited and reported on by the CPT were populated by a total of 599 women prisoners out of a total

\footnotetext{
9 The report issued to Lithuania did not contain any gender observations, the report issued to Russia did not include visits to prisons. The CPT's reports issued to Spain-Catalonia (public on 4 February 2020) Hungary (public on 17 March 2020) and France (public on 24 March 2020) fall outside the analysis criteria. The Spanish report includes a noteworthy assessment of treatment and conditions for women prisoners, which can be found here: https://www.coe.int/en/web/cpt/-/council-of-europe-anti-torture-commi ttee-publishes-report-on-spain-focusing-on-prison-and-police-establishments-in-catalonia.
} 


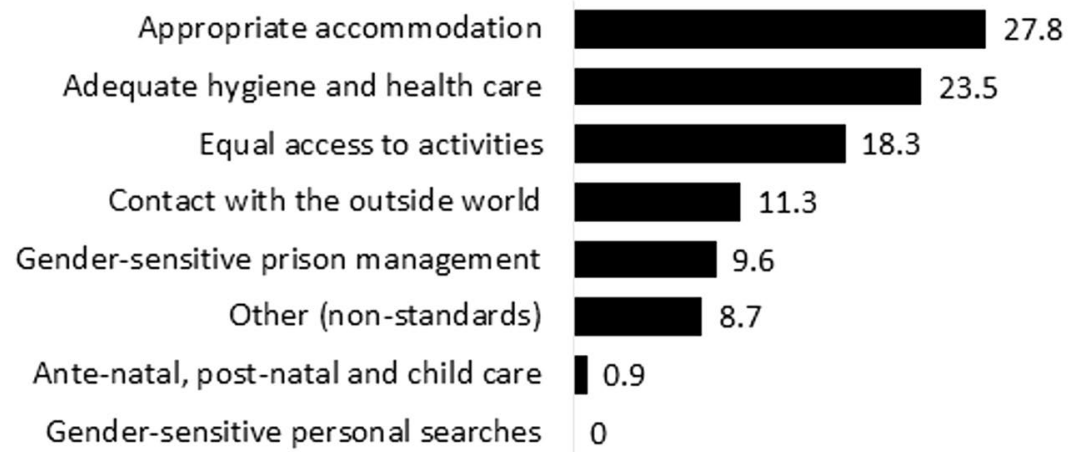

Fig. 5 Gender-Sensitive Recommendation by CPT Standard (\%, 2018 visit reports only)

population of 23,725 prisoners. None of the 2018 visit reports noted transgender prisoners.

Gender recommendations made in the 2018 reports align in many ways with the Factsheet standards (see Fig. 5). However, the CPT did not consider the gendered implications of personal searches in 2018 reports. Perhaps this oversight is because the issue of personal searches did not arise in any of the 2018 visits, or it is also possible that the CPT did not consider this standard during the visits. In other instances, the Factsheet standards fail to incorporate issues raised on numerous occasions within CPT reporting (referred to as "other" in Fig. 5). This is the case with reference to the CPT's recommendations to the Czech Republic, Romania and the UK-Scotland on admission screening processes that "include a history of any sexual abuse and other gender-based violence and that (...) should inform any care plan established for the woman to ensure appropriate care and prevent re-traumatisation" [57] II59, [65] I[84-86 and 116, [59] I[114). ${ }^{10}$ The Factsheet does not address gender-sensitive admission screening processes despite this seemingly being an area of concern for the CPT (8.7\% of gender-sensitive recommendations). Amending the Factsheet in this way would bring it in line with the CPT's own practice in this area.

On some occasions, the Factsheet standards go further than the recommendations made in CPT reports. For instance, the CPT recommended that Romania ensure it meets the special hygiene needs of women prisoners [59] I[99). However, the CPT Factsheet standard on adequate hygiene and health care draws a connection between human rights principles and the hygiene needs of women in prison, by asserting that "a failure to provide women in prison with such items can amount, in itself, to degrading treatment". It appears a missed opportunity to forego mentioning this connection within the visit report as well.

\footnotetext{
10 The CPT also discussed gender-sensitive admission screening in the 2018 UK-Northern Ireland report (visit 29 August to 6 September 2017), at $\llbracket[68,73,76$.
} 
While the CPT explicitly notes within the Women in Prison Factsheet that CPT standards are evolving in the area of women's imprisonment, the standards adopted within the Factsheet fall short when applied to women whose experience in prison is impacted by characteristics other than the fact that they are women. For example, the Factsheet standards on ante-natal, post-natal and childcare and on equal access to activities do not consider foreign prisoners who are women, and who may need special accommodations to respect cultural and religious diversity. These standards are not entirely innovative, but rather are drawn from Council of Europe Recommendation 2012(12) on Foreign Prisoners and the Bangkok Rules Rule 54. Similarly, the Factsheet does not address the needs of women who have a physical disability (EPRs, Rule 46) or women who do not know the primary language spoken in the prison (SMRs, Rule 41). When characteristics such as these intersect with gender their compound nature impacts women's experiences in the prison [14, 21] and has significant potential to lead to discrimination and other forms of ill treatment.

Alongside concerns about the CPT's lack of an intersectional approach to understanding gender discrimination in the context of prisons, the Women in Prison Factsheet standards are structured in such a way that they appear not to apply to transgender women, but are rather relevant "by analogy" to transgender prisoners. By parcelling out transgender prisoners from the Factsheet, the CPT does not fully acknowledge the needs of transgender women as they are women within the prison population. For instance, the Factsheet standards do not make explicit that transgender women may live in men's prisons and would require specialised healthcare and accommodation needs. In that the legal framework on the rights of transgender people in prison is non-existent, the CPT foregoes a great opportunity to remedy this lacuna.

\section{Conclusion}

The CPT is clear in its understanding that the prison institution is one designed for cisgender men, and that, as such, it is not a suitable environment for cisgender women. This conclusion comes across unambiguously in its assessment of conditions in Northern Ireland, where the CPT reflects on the idea of prisons as gendered institutions:

In many countries, women prisoners are treated like male prisoners with no specific rules and regulations addressing their particular needs as women. In European countries, women make up a very small minority of the overall prison population and the focus of prison systems is oriented toward the standard male prisoner. [...] However, women have particular biological and gender-specific needs and vulnerabilities that require an alternative prison policy oriented toward their requirements [64] I[65).

Despite the CPT's acknowledgment of the need to address the particular needs of cisgender women, the examination of CPT reports conducted here indicates that the CPT's approach to assessing treatment and conditions in prisons does not consistently centre the experience of imprisonment for cisgender women and 
rarely considers the needs of transgender people in prison. Although the CPT has made formal efforts to account for the gendered experience of imprisonment, our findings indicate no difference across the designated time-period in terms of the proportion of gender-sensitive observations and the gender composition of CPT delegations. However, these findings explore CPT activities across a specific three-year time-period and might differ when exploring a wider range of years.

In situations in which the CPT does consider the gendered experience of imprisonment, this is often done in relation to mental health needs and motherhood, with far less emphasis on the specific needs of transgender people, and no articulation of the treatment and conditions for cisgender and transgender women who have multiple characteristics that shape how they experience imprisonment. The inconsistency in how and when the CPT addresses gender-specific issues raises questions around the CPT's visit and reporting methodology. For instance, why did the CPT not comment on the specific situation of women in prison in three of its reports in which it visited prisons that housed women? And, by what criteria does the CPT elect to visit prisons that house cisgender women and/or transgender people in prison? In order to comprehensively assess how cisgender women and transgender men and women are treated in prison, the CPT, as well as other prison oversight bodies, must institutionalise a gender perspective within their monitoring activities. This will require oversight bodies to adopt an intersectional approach to assessment, where the treatment of cisgender women and transgender people in prison is not only related to gender, but is also impacted by other identifying characteristics. That being said, further empirical research, including ethnographic studies, survey research and in-depth interviews, can build on this study to allow for deeper exploration of the implications and value of CPT monitoring in the area of gender and imprisonment.

Given the CPT's role as a foremost prison oversight institution, its activities in the area of gender and imprisonment undoubtedly serve as a model for all prison monitoring and inspection. For this reason, amongst many others, it is imperative that the CPT respond to its own call for action [67] in the area of gendered prison monitoring: "Greater efforts are therefore needed in order to ensure a gender-sensitive monitoring of prisons, attuned to the potential compounding of problems women face in prison".

Funding PRILA has received funding from the European Research Council (ERC) under the European Union's Horizon 2020 research and innovation programme under grant agreement No [679362].

Data availability All reports analysed are publicly available on the Council of Europe online reporting database for the European Committee for the Prevention of Torture and Inhuman or Degrading Treatment or Punishment (CPT), available at https://www.coe.int/en/web/cpt/states.

\section{Declarations}

Not applicable.

Conflict of interest The authors declare they have no conflicts of interest. 
Open Access This article is licensed under a Creative Commons Attribution 4.0 International License, which permits use, sharing, adaptation, distribution and reproduction in any medium or format, as long as you give appropriate credit to the original author(s) and the source, provide a link to the Creative Commons licence, and indicate if changes were made. The images or other third party material in this article are included in the article's Creative Commons licence, unless indicated otherwise in a credit line to the material. If material is not included in the article's Creative Commons licence and your intended use is not permitted by statutory regulation or exceeds the permitted use, you will need to obtain permission directly from the copyright holder. To view a copy of this licence, visit http://creativecommons.org/licen ses/by/4.0/.

\section{References}

\section{Literature}

1. Abati, E., Brown, E., Campion, E., Khan, S., McCombe, C., da Cunha Mota, J., \& Padfield, N. (2018). Exploring the impact of Council of Europe institutions through a cross-jurisdictional collaboration. ECAN Bulletin - Howard League for Penal Reform, 39, 21-30.

2. Aizpurua, E. \& Rogan, M. (2019). La situación de las prisiones y los centros de menores en Espana: Analizando las observaciones del CPT. Boletin Criminologico, 182.

3. Armstrong, S. (2018). Securing prison through human rights: Unanticipated implications of rightsbased penal governance. The Howard Journal of Crime and Justice, 57(3), 401-421.

4. Armstrong, S. (2020). At risk of rights: Rehabilitation, Sentence Management and the structural violence of prison. Critical Criminology, 28, 85-105.

5. Beynon, J. \& Drew, N. (2005). Mental health and prisons information sheet. World Health Organization. https://www.who.int/mental_health/policy/mh_in_prison.pdf. Accessed 16 August 2019.

6. Bicknell, C., Evans, M., \& Morgan, R. (2018). Preventing torture in Europe. Strasbourg: Council of Europe.

7. Calavita, K., \& Jenness, V. (2015). Appealing to justice: Prisoner grievances, rights and carceral logic. Oakland, CA: University of California Press.

8. Carlen, P., \& Worrall, A. (2004). Analysing women's imprisonment. Devon: Willan Publishing.

9. Carlen, P. (2012). Women's imprisonment: An introduction to the Bangkok Rules. Revista Critical Penal y Poder, 3, 148-157.

10. Casale, S. (2010). The importance of dialogue and cooperation in prison oversight. Pace Law Review, 30(5), 1490-1502.

11. Cernko, D. (2014). Die umsetzung der CPT-EmpfehlungenimdeutschenStrafvollzug. Breisgau: Max Planck Institute for the Study of Crime, Security and Law.

12. Daems, T. (2017). Slaves and statues: Torture prevention in contemporary Europe. British Journal of Criminology, 57(3), 627-643. https://doi.org/10.1093/bjc/azv133.

13. Daems, T. \& Robert, L. (Eds). (2017). Europe in prisons: Assessing the impact of European institutions on national prison systems. Geneva: Palgrave Macmillan. doi:https://doi.org/10.1007/978-3319-62250-7_1.

14. Davis, A. Y., \& Shaylor, C. (2001). Race, gender, and the prison industrial complex: California and beyond. Meridians, 2, 1-25.

15. Douglas, N., Plugge, E., \& Fitzpatrick, R. (2009). The impact of imprisonment on health: What do women prisoners say? Journal of Epidemiology \& Community Health, 63(9), 749-754. https://doi. org/10.1136/jech.2008.080713.

16. Haney, C. (2001). The psychological impact of incarceration: Implications for post-prison adjustment. In From prison to home: The effect of incarceration and reentry on children, families, and communities. U.S. Department of Health \& Human Services. https://aspe.hhs.gov/basic-report/ psychological-impact-incarceration-implications-post-prison-adjustment. Accessed 3 September 2019.

17. HM Chief Inspector of Prisons for England and Wales. (2019). Annual report 2018-19.https://www. justiceinspectorates.gov.uk/hmiprisons/wp-content/uploads/sites/4/2019/07/6.5563_HMI-Priso ns-AR_2018-19_WEB_FINAL_040719.pdf, 31. Accessed 20 August 2019. 
18. Hunter, R. (2015). More than just a different face? Judicial diversity and decision-making. Current Legal Problems, 68, 119-141.

19. Jenness, V., Sexton, L., \& Sumner, J. (2019). Sexual victimization against transgender women in prison: Consent and coercion in context. Criminology, 57(4), 603-631. https://doi. org/10.1111/1745-9125.12221.

20. Jennes, V., \& Gerlinger, J. (2020). The feminization of transgender women in prisons for men: How prison as a total institution shapes gender. Journal of Contemporary Criminal Justice, 36(2), 182-205.

21. Joseph, J. (2006). Drug offenses, gender, ethnicity, and nationality: Women in prison in England and Wales. The Prison Journal, 86(1), 140-157. https://doi.org/10.1177/0032885505283926.

22. Karamalidou, A. (2017). Embedding human rights in prison: English and Dutch perspectives. London: Palgrave MacMillan.

23. Kenney, S. J. (2013). Gender \& justice: Why women in the judiciary really matter. Abingdon: Routledge Press.

24. Lamble, S. (2012). Rethinking gendered prison policies: Impacts on transgender prisoners. ECAN Bulletin - Howard League for Penal Reform, 16, 7-12.

25. Lappi-Seppälä, T., \& Koskenniemi, L. (2018). National and regional instruments in securing the rule of law and human rights in the Nordic prisons. Crime, Law and Social Change, 70(1), 135-159. https://doi.org/10.1007/s10611-017-9723-1.

26. Lydon, J. Carrington, K., Low, H., Miller, R., \& Yazdy, M. (2015). Coming out of concrete closets: A report on black \& pink's national LGBTQ prisoner survey. https://www.issuelab.org/resou rces/23129/23129.pdf. Accessed 30 June 2019.

27. Mitchell, M. \& Howarth, C. (2009) Trans research review. UK Equality and Human Rights Commission. https://www.equalityhumanrights.com/sites/default/files/research_report_27_trans_resea rch_review.pdf. Accessed 9 June 2019.

28. Moore, L., \& Scranton, P. (2016). Doing gendered Time: The harms of women's imprisonment. In Y. Jewkes, B. Crewe, \& J. Bennett (Eds.), Handbook on Prisons (2nd ed., pp. 549-567). London: Routledge.

29. Morgan, R., \& Evans, M. (1999). Protecting prisoners: The standards of the European Committee for the Prevention of Torture in context. Oxford: Oxford University Press.

30. Murdoch, J. (2006). Tackling ill-treatment in places of detention: The work of the Council of Europe's “Torture Committee." European Journal of Criminal Policy Research, 12, 121-142. https ://doi.org/10.1007/s10610-006-9011-6.

31. Organization for Security and Co-operation in Europe (OSCE). (2019). Preventing and addressing sexual and gender-based violence in places of deprivation of liberty standards, approaches and examples from the OSCE region.

32. Piacentini, L., \& Katz, E. (2017). Carceral framing of human rights in Russian prisons. Punishment \& Society, 19(2), 221-239. https://doi.org/10.1177/1462474516665609.

33. Rackley, E. (2013). Women, judging and the judiciary: From difference to diversity. Abingdon: Routledge Press.

34. Sevelius, J., \& Jenness, V. (2017). Challenges and opportunities for gender-affirming healthcare for transgender women in prison. International Journal of Prisoner Health, 13(1), 32-40. https://doi. org/10.1108/IJPH-08-2016-004.

35. Sexton, L., Jenness, V., \& Sumner, J. M. (2010). Where the margins meet: A demographic assessment of transgender inmates in men's prisons. Justice Quarterly, 27(6), 835-866. https://doi. org/10.1080/07418820903419010.

36. van der Valk, S., Aizpurua, E. \& Rogan, M. (2020). Guess who? Patterns and correlates of familiarity with prison oversight bodies among prisoners. 20th Annual Conference of the European Society of Criminology. Online (11 September).

37. Vauchez, H. (2015). More women - but which women? The rule and the politics of gender balance at the european court of human rights. European Journal of International Law, 26(1), 195-221.

38. Walmsley, R. (2006). Women in prison list $1^{\text {st }}$ edition. https://www.prisonstudies.org/sites/default/ files/resources/downloads/women-prison-list-2006.pdf. Accessed 6 June 2019.

39. Walmsley, R. (2017a). Women in prison list 4th edition. https://www.prisonstudies.org/sites/default/ files/resources/downloads/world_female_prison_4th_edn_v4_web.pdf. Accessed 6 June 2019.

40. Walmsley, R. (2017). Variations and growth in the levels of female imprisonment. In P. H. van Kempen \& M. Krabbe (Eds.), Women in Prison (pp. 105-118). Cambridge: Intersentia. 
41. Whittle, S., Turner, L. \& Al-Alami, M. (2007) Engendered penalties: Transgender and transsexual people's experiences of inequality and discrimination, The Equalities Review. https://www.ilgaeurope.org/sites/default/files/trans_country_report_-_engenderedpenalties.pdf. Accessed 15 August 2019.

42. Winter, S., Diamond, M., Green, J., Karasic, D., Reed, T., Whittle, S., \& Wylie, K. (2016). Transgender people: Health at the margins of society. The Lancet, 23(388), 390-400. https://doi. org/10.1016/S0140-6736(16)00683-8.

43. Wolff, N., Blitz, C. L., Shi, J., Bachman, R., \& Siegel, J. A. (2006). Sexual violence inside prisons: Rates of victimization. Journal of Urban Health, 83(5), 835-848. https://doi.org/10.1007/s1152 4-006-9065-2.

44. World Prison Brief. (2018). Highest to lowest - Female prisoners (percentage of prison population). International Centre for Prison Studies. https://www.prisonstudies.org/highest-to-lowest/femal e-prisoners?field_region_taxonomy_tid=14. Accessed 7 June 2019.

45. Wright, E. M., van Voorhis, P., Salisbury, E. J., \& Bauman, A. (2012). Gender-responsive lessons learned and policy implications for women in prison: A review. Criminal Justice and Behavior, 39(12), 1612-1632. https://doi.org/10.1177/0093854812451088.

\section{Legal Documents}

46. Body of Principles for the Protection of All Persons Under Any Form of Detention of Imprisonment (“1988 Principles”) G.A. Res. 43/173 (1988).

47. European Convention for the Prevention of Torture and Inhuman or Degrading Treatment or Punishment (ECPT), CPT/Inf/C/2002 (1987).

48. European Prison Rules, Recommendation Rec(2006)2 of the Committee of Ministers, revised 1 July 2020.

49. Principles on the Application of International Human Rights Law in Relation to Sexual Orientation and Gender Identity ("Yogyakarta Principles") (2007).

50. United Nations Convention against Torture and Other Cruel, Inhuman or Degrading Treatment or Punishment ("UNCAT”) G.A. Res. 39/46 (1984).

51. United Nations Rules for the Treatment of Women Prisoners and Non-custodial Measures for Women Offenders ("The Bangkok Rules") G.A. Res. A/RES/65/229 (2011).

52. United Nations Standard Minimum Rules for the Treatment of Prisoners ("The Nelson Mandela Rules") G.A. Res. 70/175 (2015).

\section{CPT Reports and Documents}

53. Report to the Azerbaijani Government (29 March to 8 April 2016) CPT/Inf (2018a) 35.

54. Report to the Azerbaijani Government (23 to 30 October 2017) CPT/Inf (2018b) 37.

55. Report to the Belgium Government (27 March to 6 April 2017) CPT/Inf (2018) 8.

56. Report to the Croatian Government (14 to 22 March 2017) CPT/Inf (2018) 44.

57. Report to the Czech Government (2 to 11 October 2018) CPT/Inf (2019) 23.

58. Report to the Estonian Government (27 September to 5 October 2017) CPT/Inf (2019) 31.

59. Report to the Romanian Government (7 to 19 February 2018) CPT/Inf (2019) 7.

60. Report to the Government of Serbia (31 May to 7 June 2017) CPT/Inf (2018) 21.

61. Report to the Italian Government (8 to 21 April 2016) CPT/Inf (2017) 23.

62. Report to the Spanish Government (27 September to 10 October 2016) CPT/Inf (2017) 34.

63. Report to the Government of the United Kingdom - England (30 March to 12 April 2016) CPT/Inf (2017) 9.

64. Report to the Government of the United Kingdom - Northern Ireland (29 August to 6 September 2017) CPT/Inf (2018) 47.

65. Report to the Government of the United Kingdom - Scotland (17 to 25 October 2018) CPT/Inf (2019) 29.

66. Women Deprived of Liberty. (2000). (Extract from the 10th General Report of the CPT) CPT/ $\operatorname{Inf}(2000) 13$-part.

67. Women in Prison Factsheet. (2018). CPT/Inf(2018) 5. 


\section{ECtHR Cases}

68. Uyan v Turkey, Appl. no. 7454/04, Judgment of 10 February 2006.

69. Enache v Romania, Appl. no. 10662/06, Judgment of 1 April 2014.

70. Khamtokhu et Aksenchik v Russia, Appl. no. 60367/08 and Appl. no. 961/11, Judgment of 24 January 2017.

71. Ecis v Latvia, Appl. no. 12879/09, Judgment of 1 January 2019.

Publisher's note Springer Nature remains neutral with regard to jurisdictional claims in published maps and institutional affiliations. 